Gynäkologe 2016 · 49:786-794

DOI 10.1007/s00129-016-3966-2

Online publiziert: 16 . September 2016

๑) Springer-Verlag Berlin Heidelberg 2016

\section{Redaktion}

T. Fehm, Düsseldorf

W. Janni, Ulm

R. Kimmig, Essen

N. Maass, Kiel

CrossMark

loannis Mylonas ${ }^{1,8}$. Stefan Dieterle ${ }^{2} \cdot$ Monika Hampl $^{3}$. Udo B. Hoyme ${ }^{4}$. Julia Jückstock ${ }^{1}$. Werner Mendling ${ }^{5} \cdot$ Gerd Neumann $^{6} \cdot$ Klaus Friese $^{7}$

${ }^{1}$ Klinik und Poliklinik für Frauenheilkunde und Geburtshilfe - Klinikum Innenstadt, Ludwig-MaximiliansUniversität München, München, Deutschland

${ }^{2}$ Institut für gynäkologische Endokrinologie und Reproduktionsmedizin - Gynäkologie und Geburtshilfe, Universität Witten/Herdecke, Dortmund, Deutschland

${ }^{3}$ Frauenklinik, Universität Düsseldorf, Düsseldorf, Deutschland

${ }^{4}$ Klinik für Frauenheilkunde und Geburtshilfe, Ilm-Kreis-Kliniken, Arnstadt, Deutschland

${ }^{5}$ Deutsches Zentrum für Infektionen in Gynäkologie und Geburtshilfe, Wuppertal, Deutschland

${ }^{6}$ Facharzt für Frauenheilkunde und Geburtshilfe, Potsdam, Deutschland

${ }^{7}$ Abteilung Gynäkologie, Klinik Bad Trissl, Oberaudorf, Deutschland

${ }^{8}$ Arbeitsgemeinschaft für Infektionen und Infektionsimmunologie (AGII), Deutsche Gesellschaft für Gynäkologie und Geburtshilfe (DGGG), Berlin, Deutschland

\title{
Zika-Virus-Infektion in der Gynäkologie und Geburtshilfe
}

\section{Stellungnahme der AG für Infektionen und Infektionsimmunologie der DGGG}

\section{Hintergrund}

Die Weltgesundheitsorganisation (WHO) hat am 1. Februar 2016 aufgrund eines möglichen epidemiologischen Zusammenhangs einer Zika-Virus-Infektion mit fetalen neurologischen Auffälligkeiten [66] eine ,public health emergency of international concern" (PHEIC) ausgerufen. Eine PHEIC ist als ein plötzliches Ereignis zu werten, dass sich weltweit ausbreiten kann und dadurch ein international relevantes Gesundheitsrisiko darstellt [65]. Vor allem die mögliche Assoziation zwischen einer Infektion während der Schwangerschaft und einer fetaler Mikrozephalie hat sowohl die WHO als auch die lokalen Gesundheitsbehörden der betroffenen Länder zum sofortigen Handeln geleitet. Mittlerweile ist die Kausalität zwischen dem Zika-Virus und einer fetalen Mikrozephalie oder auch einem Guillain-BarréSyndrom (GBS) beim Erwachsenen wissenschaftlich (fast) gesichert.

Das Zika-Virus ist genetisch mit dem Dengue-Virus (DENV-1 bis DENV-4), dem West-Nil-Virus (WNV), dem Gelbfieber-Virus (YFV) und dem Japanischen Enzephalitis-Virus (JEV) verwandt [33,
41] und wurde im Jahre 1947 in Uganda bei einem Rhesusaffen isoliert [21-23]. Bis zum Jahr 2007 wurden nur sporadisch auftretende Infektionen, meistens im tropischen Afrika und in Südostasien, beobachtet. Allerdings kam es in den letzten 10 Jahren zu einigen großen epidemischen Ausbrüchen. Zwischen Januar 2007 und Juni 2016 wurde in insgesamt 66 Staaten bzw. Regionen eine ZikaVirus-Übertragung beobachtet. Auf dem amerikanischen Kontinent hat sich die jetzige Epidemie in mittlerweile 25 Ländern ausgebreitet [66].

\section{》) Die Kausalität zwischen Zika- Virus und fetaler Mikrozephalie gilt mittlerweile als gesichert}

Durch die Globalisierung und die weltweit veränderten Reisegewohnheiten haben sowohl die WHO als auch lokale Gesundheitsbehörden das Risiko erkannt und unterschiedliche Maßnahmen ergriffen. Bekanntermaßen ist der primäre Ausbruch in Mittel- bzw. Südamerika zu lokalisieren. Allerdings nehmen die Bedenken der Verbreitung des Virus in den europäischen Ländern weiterhin zu. Vor allem aufgrund der anstehenden Urlaubszeit und der sportlichen Großereignissen (z. B. Olympische und Paraolympische Spiele in Brasilien) besteht ein sehr großer Informationsbedarf.

\section{Epidemiologie}

Bis zum Ende des letzten Jahrzehnts wurden nur vereinzelte Infektionen bzw. Ausbrüche beobachtet. Diese fanden v. a. im afrikanischen bzw. südostasiatischen Raum statt. Die ersten großen epidemischen Ausbrüche des Zika-Virus erfolgten im Jahr 2007 in Mikronesien, wobei keine schwerwiegenden bzw. tödlichen Verläufe beobachtet wurden [24, 35]. Im Jahr 2013 wurde ein weiterer Ausbruch in Französisch-Polynesien beobachtet, wobei wahrscheinlich über 29.000 Einwohner ärztliche Hilfe in Anspruch nahmen. Hier wurde auch erstmalig von 72 Fällen mit teils schwerwiegenden neurologischen Komplikationen berichtet [12, 18, 33, 40, 48].

Im Zeitraum zwischen Oktober 2015 und April 2016 wurden mehr als 7150 suspekte Fälle einer Mikrozephalie bzw. einer Fehlentwicklung des zentralen Nervensystems in den nordöstlichen Bezir- 


\begin{tabular}{|ll}
\hline $\begin{array}{l}\text { Tab. } 1 \\
\text { gnosen einer Zika-Virus-Infektion }\end{array}$ \\
\hline Viren & Dengue-Fieber \\
\cline { 2 - 2 } & Chikungunya-Virus \\
\cline { 2 - 2 } & Masern \\
\cline { 2 - 2 } & Röteln \\
\cline { 2 - 2 } & Parvovirus B19 \\
\cline { 2 - 2 } & Enteroviren \\
\hline Bakterien & Adenoviren \\
& $\begin{array}{l}\text { Streptokokken der Gruppe A } \\
\text { (GAS) }\end{array}$ \\
\cline { 2 - 2 } & Rickettsien \\
\cline { 2 - 2 } & Leptospiren \\
\hline Parasiten & Malaria \\
\hline
\end{tabular}

ken von Brasilien berichtet [66]. Dies ist ein deutlicher Anstieg der Fallzahlen, da im Zeitraum von 2001-2014 nur durchschnittlich 163 Fälle pro Jahr gemeldet wurden [66]. Dieser sehr beeindruckende epidemiologische Unterschied war der erste Anlass, einen Zusammenhang zwischen fetalen Fehlbildungen und einer Zika-Virus-Infektion zu vermuten. Diese Vermutung wurde zuerst von den lokalen brasilianischen Behörden gestellt und von der WHO übernommen und auch bestätigt.

Insgesamt wurden mittlerweile weltweit 1679 dokumentierte und bestätigte Fälle einer Mikrozephalie und/oder einer Malformation des zentralen Nervensystems (ZNS) bei Verdacht auf eine kongenitale Infektion in 12 Ländern berichtet [67].

\section{Risiko einer Zika-Virus- Übertragung in Europa}

Das Gesamtrisiko einer Zika-VirusÜbertragung im Frühjahr und im Sommer dieses Jahres scheint in Europa nur gering bis mäßig zu sein [30]. Allerdings haben laut WHO 3 europäische Länder ein höheres Risiko, da der primäre Vektor, die Mücke Aedes aegypti, dort vorkommt: die portugiesische Insel Madeira und die nordöstliche Schwarzmeerküste (Georgien und der südliche Teil der Russischen Föderation). Allerdings existiert auch ein moderates Risiko einer möglichen ZikaVirus-Ausbreitung in 18 europäischen Ländern v. a. im Mittelmeerraum, darunter beliebte Sommerferienziele, wie
Frankreich, Griechenland, Italien oder Spanien, [30]. Diese Länder haben im Lauf der letzten Monate etliche Vorkehrungen getroffen. Die Minimierung der Mückenpopulation wurde, wie fast jedes Jahr in den europäischen Mittelmeerländern, verstärkt durchgeführt.

\section{》) Eine Übertragung durch Geschlechtsverkehr auf Reisende in Endemiegebieten ist möglich}

Für Mittel- und Nordeuropa gibt die WHO allerdings eine Entwarnung, da die primären Übertragungsvektoren dort nicht heimisch sind. Allerdings ist eine Übertragung durch andere Möglichkeiten (v. a. Geschlechtsverkehr) auf Reisende in Endemiegebieten weltweit möglich. Seit Einführung einer Meldepflicht in Deutschland im Mai 2016 sind durch das Robert Koch-Institut (RKI) bisher 17 Fälle von Zika-Virus-Infektionen, darunter 10 Frauen, erfasst [19]. Allerdings war keine dieser infizierten Patientinnen schwanger. Die Dunkelziffer müsste in Deutschland allerdings höher sein, da nicht alle Patientinnen und Patienten nach einer Rückreise bzw. mit einem oligosymptomatischen Verlauf einen Arzt aufsuchen.

\section{Primäre Übertragung durch Mückenstiche}

Das Zika-Virus wird hauptsächlich durch den Stich von infizierten Mücken v. a. der Gattung Aedes übertragen. Die AedesArten können sich in sehr geringen Wassermengen vermehren, wobei die Eier sehr resistent gegenüber Umwelteinflüssen sind. Dabei spielt v. a. die Gelbfiebermücke (Aedes aegypti), die in den Subtropen und Tropen weit verbreitet ist, eine wesentliche Rolle.

Während die Gelbfiebermücke der wichtigste Vektor in Südamerika zu sein scheint, könnten auch die anderen Moskitoarten zur Übertragung des Virus beitragen. In Mitteleuropa sind v. a. die asiatischen Tigermücken (Aedes albopictus) vereinzelt anzutreffen und könnten somit einen möglichen Vektor darstellen. Vor allem eine mögliche Übertragung durch diese Mückenart beinhaltet etliche Probleme, da sie nicht nur tagaktiv ist, sondern auch mehrere Personen im Lauf ihres Lebenszyklus stechen kann und somit einen effizienten Überträger von Erkrankungen darstellt.

\section{Sexuelle Übertragung}

Mittlerweile wurde eine Übertragung durch Geschlechtsverkehr in 10 Ländern beschrieben [26, 32, 38, 63]. Auch in Deutschland ist ein Fall einer sexuellen Übertragung bekannt geworden [27]. Bei allen Übertragungen waren symptomatische Männer mit Reiseanamnese in die Endemiegebiete beteiligt.

Der Übertragungsweg erfolgte durch ungeschützten vaginalen Geschlechtsverkehr, wobei alle Frauen kurz danach Symptome einer Zika-Virus-Infektion entwickelten. Das Virus wurde in 2 Fällen aus dem Sperma isoliert [36, 43]. Interessanterweise konnte das Virusgenom sogar 62 Tage nach Beginn der Symptome nachgewiesen werden $[4,58]$, länger als bei einer bestehenden Virämie, die 7 Tage betragen kann. Somit wäre theoretisch eine Übertragung auch nach der virämischen Phase mittels sexueller Kontakte möglich.

Da eine sexuelle Übertragung trotz der bislang geringen dokumentierten Fallzahl möglich ist [16, 32, 43, 63], müssen noch weitere klärende Studien bzw. Untersuchungen erfolgen. Vor allem sollte geklärt werden, ob eine Übertragung durch Geschlechtsverkehr auch von Frauen auf ihre Partner erfolgen kann und wie lange eine virale Ausscheidung im Genitalbereich stattfindet bzw. relevant ist.

\section{Übertragung während Schwangerschaft und Wochenbett}

Das Zika-Virus kann, auch wenn der Pathomechanismus noch derzeit unbekannt ist, die Plazentaschranke überwinden, da die virale RNA in der Amnionflüssigkeit bei schwangeren Frauen mit der Diagnose einer fetalen Mikrozephalie nachgewiesen wurde [49]. Kürzlich konnten Zika-Virus-IgM-Antikörper in der Gehirnflüssigkeit bei 97 \% und im Se- 
Gynäkologe 2016·49:786-794 DOI 10.1007/s00129-016-3966-2

(c) Springer-Verlag Berlin Heidelberg 2016

\section{Mylonas · S. Dieterle · M. Hampl · U. B. Hoyme · J. Jückstock · W. Mendling · G. Neumann · K. Friese}

\section{Zika-Virus-Infektion in der Gynäkologie und Geburtshilfe. Stellungnahme der AG für Infektionen und Infektionsimmunologie der DGGG}

\section{Zusammenfassung}

Das Zika-Virus wird hauptsächlich durch den

Stich von infizierten Mücken übertragen. Auch eine Übertragung durch Geschlechtsverkehr ist möglich. In bis zu $80 \%$ der Fälle ist der Infektionsverlauf a- bzw. oligosymptomatisch, wobei die meisten Symptome nur 7 Tage anhalten. Die wichtigsten klinischen Manifestationen sind Hauterscheinungen, Fieber, Arthralgie bzw. arthritisähnliche Beschwerden und eine nichteitrige Konjunktivitis. Das Zika-Virus ist mit einer Reihe von neurologischen Erkrankungen (z. B. Guillain-Barré-Syndrom) beim Erwachsenen und einer fetalen Mikrozephalie während der Schwangerschaft assoziiert. Während das Risiko einer Mikrozephalie bei einer
Infektion im 1. Trimenon zwischen 1 und $47 \%$ berechnet wurde, scheint das entsprechende Risiko bei einer Infektion im 2. und 3. Trimenon vernachlässigbar zu sein. Für den Nachweis des Virus werden molekularbiologische Methoden genutzt. Schwangere, die kürzlich eine Reise in Endemiegebiete hinter sich haben, können getestet werden. Erweiterte Ultraschalluntersuchungen werden für alle Schwangeren empfohlen, die in Zika-VirusEndemiegebieten leben oder dorthin gereist sind. Bei Müttern mit positivem Testergebnis sollten sequenzielle Ultraschalluntersuchungen alle 3-4 Wochen erfolgen. Eine manifeste Erkrankung wird symptomatisch mit Schmerzmitteln, fiebersenkenden Medikamenten und der Zufuhr von reichlich Flüssigkeit behandelt. Schwangere sollten berufliche und private Reisen in Zika-Virus-Endemiegebiete vermeiden bzw. Vorkehrungen zum Schutz vor Mückenstichen treffen. Da eine sexuelle Übertragung möglich ist, sollten Männer von schwangeren Frauen, die in Zika-VirusEndemiegebieten wohnen oder dorthin reisen, entweder keinen Geschlechtsverkehr haben oder konsequent Kondome über den gesamten Zeitraum der Schwangerschaft nutzen.

Schlüsselwörter

Arboviren - Schwangerschaft - Mikrozephalie · Prävention · Diagnostik

\section{Zika virus infection in gynecology and obstetrics. Statement from the DGGG Infectious Immunology Working Group}

\section{Abstract}

The Zika virus is transmitted predominantly via the bite of infected mosquitoes. Sexual transmission is also possible. In up to $80 \%$ of cases, the course of infection is asymptomatic or oligosymptomatic, the majority of symptoms lasting for only 7 days. The most important symptoms are skin reactions, fever, arthralgia or arthritis-like complaints, and nonpurulent conjunctivitis. The Zika virus is associated with various neurologic diseases (e.g., Guillain-Barré syndrome) in adults, as well as with fetal microcephaly during pregnancy. Whereas the risk of microcephaly resulting from infection during the first trimester has been estimated between 1 and $47 \%$, the corresponding risk due to infection in the second and third trimesters appears to be negligible. Pregnant women who have recently travelled in endemic regions could be tested. Extended ultrasound examinations are recommended for all pregnant women who live or have travelled in a Zika virus endemic region. Mothers testing positive should undergo sequential ultrasound examinations every 3-4 weeks. Symptomatic treatment of manifest disease employs analgesics and antipyretics, as well as ample fluid intake. Pregnant women should avoid business trips and private travel to Zika virus endemic regions. If this is unavoidable, precautionary measures should be taken to guard against mosquito bites. Since sexual transmission is possible, male partners of pregnant women, who live in or travel to Zika virus endemic regions, should either refrain from sexual intercourse or use condoms for the entire duration of the pregnancy.

Keywords

Arboviruses - Pregnancy · Microcephaly .

Prevention · Diagnostics rum bei $90 \%$ von 31 untersuchten Neugeborenen mit Mikrozephalie festgestellt werden [14], was wiederum sowohl auf die Überwindung der Plazentabarriere als auch auf eine neurotrope Wirkung des Virus hinweist [14].

Obwohl das Virus in der Muttermilch nachgewiesen werden konnte, sind derzeit noch keine Übertragungsfälle auf das Neugeborene berichtet worden. Zurzeit wird Frauen in Endemiegebieten empfohlen, weiter zu stillen $[9,25,62]$.

\section{Klinischer Befund}

\section{Allgemeine Symptomatik}

In bis zu $80 \%$ der Fälle ist der Infektionsverlauf a- bzw. oligosymptomatisch, wobei die meisten Symptome nur 7 Tage anhalten [24, 26, 51, 60]. Die Inkubationszeit liegt zwischen 3 und 12 Tagen.

Die wichtigsten Symptome sind Fieber und Kopfschmerzen [7, 60]. Nach der Epidemie im Jahre 2007 wurden an 31 Patienten die folgenden Symptome ebenfalls beobachtet:
- Hauterscheinungen,

- Fieber,

- Arthralgie bzw. arthritisähnliche Beschwerden,

- nichteitrige Konjunktivitis [24].

Die derzeitige Definition des Erkrankungsbilds beinhaltet mindestens 2 dieser 4 Symptome [47]. Da die bestehenden Symptome sehr uncharakteristisch sind, sollten auch weitere Infektionserkrankungen differenzialdiagnostisch in Erwägung gezogen werden (• Tab. 1). Vor allem Dengue- bzw. ChikungunyaVirus-Infektionen verursachen ähnliche 


\begin{tabular}{|ll}
\hline $\begin{array}{l}\text { Tab. } 2 \\
\text { chen einer Mikrozephalie }[3,28,44]\end{array}$ \\
\hline $\begin{array}{ll}\text { Genetische } \\
\text { Ursachen }\end{array}$ & Sporadisch \\
\cline { 2 - 2 } & Klinische Syndrome \\
\hline Verletzungen & Z. B. Trauma \\
\hline Infektionen & $\begin{array}{l}\text { Herpes-simplex-Virus } \\
\text { (HSV) }\end{array}$ \\
\cline { 2 - 2 } & Parvovirus B19 \\
\cline { 2 - 2 } & Röteln \\
\cline { 2 - 2 } & Toxoplasmose \\
\cline { 2 - 2 } & Treponemapallidum \\
\cline { 2 - 2 } & Windpocken \\
\hline $\begin{array}{l}\text { Teratogenegalie-Virus (CMV) } \\
\text { Substanzen }\end{array}$ & Medikamente \\
\cline { 2 - 2 } $\begin{array}{l}\text { Mangel- } \\
\text { erscheinungen } \\
\text { bzw. } \\
\text { Erkrankungen }\end{array}$ & $\begin{array}{l}\text { Mütterlicher Hypothy- } \\
\text { reoidismus }\end{array}$ \\
\cline { 2 - 2 } & Mangelernährung \\
\cline { 2 - 2 } & Folsäuremangel \\
\hline
\end{tabular}

Symptome, kommen in den gleichen geographischen Regionen vor und werden sogar vom gleichen Vektor übertragen $[24,31,33]$, sodass bei bestehender Reiseanamnese und klinischer Symptomatik u. a. an diese Differenzialdiagnosen gedacht werden sollte.

Mittlerweile sind makulopapulöse Hauterscheinungen die wichtigsten Symptome, die bei $90 \%$ aller infizierten Patienten auftreten und die denen von Masern ähneln [29, 33, 68]. Die Arthralgie bzw. die arthritisähnlichen Symptome manifestieren sich an den kleinen Gelenken der Extremitäten und können bis $\mathrm{zu}$ einem Monat persistieren [68]. Seltenere Manifestationen einer Zika-Virus-Infektion beinhalten unspezifische Krankheitsgefühle, Druck hinter den Augen, Schwindel, Anorexie, Magenbeschwerden, Aphten, Hämatospermie oder Prostatitis [2, 12, 26, 33, 35, 43].

Schwere klinische Verläufe mit notwendigem Krankenhausaufenthalt sowie infektionsbedingte Todesfälle sind zwar möglich, werden aber als selten eingeschätzt und betrafen bislang nur Personen mit ausgeprägten Vorerkrankungen [24, 37, 68].

\section{Neurologische Erkrankungen}

Das Zika-Virus ist mit einer Reihe von neurologischen Erkrankungen beim Erwachsenen assoziiert. Das Virus kann die Plazenta infizieren und überwinden [39, $46,56,64]$ und somit durch die Infektion von kortikalen neuronalen Stammzellen über eine herbeigeführte Apoptose und Autophagie die neuronale Entwicklung beeinflussen [15].

\section{Guillain-Barré-Syndrom}

Während die meisten Zika-Virus-Infektionen selbstlimitierend ohne schwerwiegende Folgen waren, konnte aufgrund einer Fall-Kontroll-Untersuchung aus der Epidemie in Französisch-Polynesien im Jahre 2013 ein erster wissenschaftlich belegter Zusammenhang zwischen ZikaVirus-Infektion und GBS gezeigt werden [11]. Während dieses Ausbruchs war die Inzidenz eines GBS um das 20-Fache erhöht [48]. Das GBS ist eine Autoimmunerkrankung, die das periphere Nervensystem befällt und zu einem Verlust der neuronalen Markscheiden führt, was zu Gesichtslähmungen, Muskelschmerzen, Muskelfunktionsstörungen bis hin zur Paralyse der Extremitäten bzw. der Atemmuskulatur führt. Ein ähnlicher Zusammenhang konnte auch im derzeitigen Endemiegebiet beobachtet werden [48].

\section{Mikrozephalie}

Eine Mikrozephalie kann mehrere Ursachen haben (•Tab. 2). Darunter zählen auch Toxoplasmose, Treponema pallidum, Windpocken, Parvovirus B19, Röteln, Zytomegalie-Virus (CMV) oder Herpes-simplex-Virus (HSV) [3, 28, 44]. Das Zika-Virus wird mittlerweile als eine neue infektiöse Ursache der Mikrozephalie angesehen [57]. Dabei werden die betroffenen Kinder mit einem $\mathrm{zu}$ kleinen Kopf geboren, schwerwiegende neurologische Störungen und geistige Behinderung kommen manchmal hinzu. Allerdings wird noch das genaue Ausmaß dieses Zusammenhangs der bereits beschriebenen Fälle diskutiert.

Anhand der Zika-Virus-Epidemie in Französisch-Polynesien wurde das Risi- ko einer Mikrozephalie von Kindern, die von im ersten Trimenon infizierten Müttern geboren wurden, auf etwa $1 \%$ geschätzt. Hingegen wurden in einer Kohortenuntersuchung aus Brasilien kindliche Auffälligkeiten (einschließlich Totgeburten, Wachstumsretardierungen und Mikrozephalie) bei $29 \%$ der Feten von infizierten Müttern während aller Trimester beobachtet $[10,13]$.

Die Einschätzung des Risikos, nach einer Infektion ein Kind mit neurologischen Auffälligkeiten zu gebären, ist derzeit überaus schwierig. In einer FallKontroll-Studie aus der Epidemie in Polynesien wurde die Häufigkeit einer Mikrozephalie nach Infektion im 1. Trimenon mit etwa 1:100 pro 10.000 infizierte Schwangere (95 Fälle (95\%-Konfidenzintervall [95\%-KI] 34-191)) angegeben mit einer normalen Mikrozephalieprävalenz von 0,02\% [13]. Nach Auswertung der Daten aus der Region Bahia (Brasilien) wird das Risiko, ein Kind mit Mikrozephalie nach einer Infektion im 1. Trimenon zu entbinden, ebenfalls auf $1-13 \%$ geschätzt [34].

\section{》) Das Risiko einer Mikroze- phalie bei einer Infektion im 1. Trimenon wurde mit bis zu $46,7 \%$ berechnet}

In einer statistischen Analyse, in der die Sekundärdaten aus der Brasilienepidemie mithilfe mathematischer Modelle analysiert wurden, wurde eine Übertragungswahrscheinlichkeit von $30 \%$ für eine Zika-Virus-Infektion bei einer seronegativen Erkrankung als Grundlage genommen [45]. Dabei wurde das Risiko einer Mikrozephalie bei einer Infektion im 1. Trimenon mit 46,7 \% (95\%-KI: 9,1-84,2) berechnet [45], was mit dem Risiko eines kongenitalen $\mathrm{Ru}$ bellasyndroms (CRS) nach Infektion im 1. Trimenon vergleichbar ist [28]. Allerdings variiert das generelle Risiko einer Mikrozephalie zwischen 14 und $100 \%$ [45]. Während das Risiko einer Mikrozephalie bei einer Infektion im 1 . Trimenon zwischen 1 und $47 \%$ angegeben bzw. errechnet wurde, scheint das entsprechende Risiko bei einer Infektion 


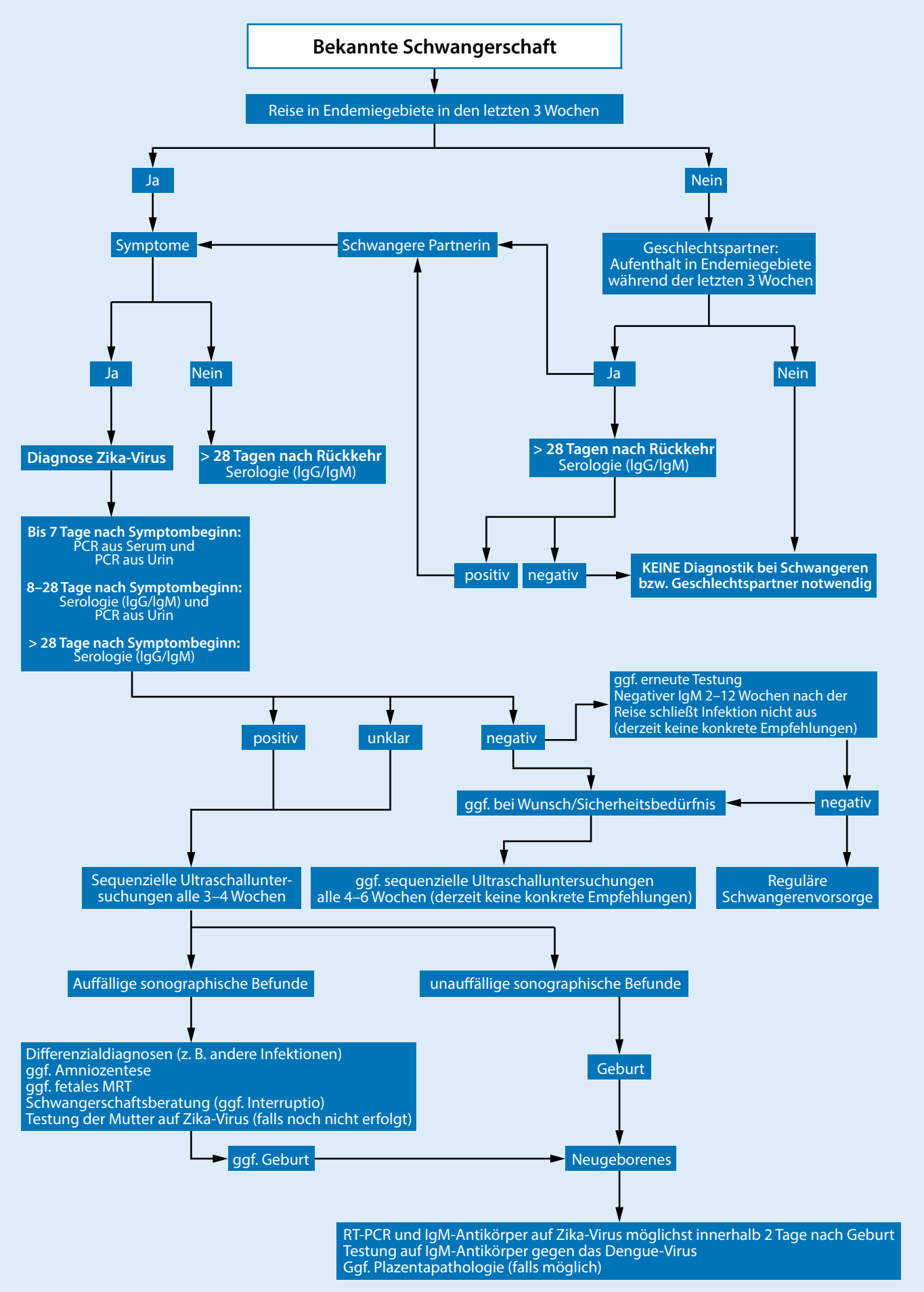

Abb. $1 \triangleleft$ Algorithmus bei Zika-Virus-Infektion. MRT Magnetresonanztomographie, $P C R$ Polymerase-Kettenreaktion, $R T$ reverse Transkription

im 2. und 3. Trimenon vernachlässigbar zu sein [34]. Dies wird durch eine aktuelle Untersuchung in Kolumbien bestätigt, wo Schwangere, die sich im 3. Trimenon infiziert hatten, alle gesunde und unauffällige Kinder zur Welt brachten [53].

\section{Diagnostik}

Die klinische Diagnose einer Zika-Virus-Infektion ist aufgrund von ähnlichen klinischen Symptomen anderer Erkrankungen durch Arboviren erschwert. Hinzu kommt, dass sowohl das Dengue-Virus als auch das Chikungunya-Virus in den gleichen geographischen Gebieten vorkommt. Auch können andere Infektionserkrankungen ähnliche Symptome auslösen (•Tab. 1).

Demzufolge werden molekularbiologische Methoden genutzt, um die virale RNA nachzuweisen. Daneben können IgG- und IgM-Antikörper im Serum 


\section{Infobox 1 Diagnostik bei Schwangeren mit Reiseanamnese in Endemiegebiete}

- Mit Symptomen:

- Eine Testung auf Zika-Virus mithilfe einer Polymerase-Kettenreaktion (RT-PCR) oder durch Nachweis von IgM wird empfohlen

- Ohne Symptome:

Eine Antikörpertestung nach einer Reise in Endemiegebiete kann angeboten werden ( $\lg G$ und $\lg M$ )

bestimmt werden. Für die Antikörperbestimmung stehen etliche Methoden, einschließlich indirekte Immunfluoreszenztest (IFT) oder Enzymimmunoassay (EIA), zur Verfügung. Allerdings kann es aufgrund der Fülle genetischer und antigener Ähnlichkeit mit anderen Flaviviren (z. B. Dengue-Virus) zu Kreuzreaktionen kommen. Ein positiver Antikörpernachweis kann mittels Neutralisationstest weiter abgeklärt werden [35], wobei dieser derzeit nur in Speziallaboratorien durchgeführt wird.

\section{Molekularbiologischer Nachweis einer Zika-Virus-Infektion}

Das virale Genom konnte im Blut (Serum und Plasma), Speichel, Sperma und Urin $[17,29,42,43]$ nachgewiesen werden. Interessanterweise konnte die virale RNA bis zu 3 Wochen nach Beginn der klinischen Symptome im Urin festgestellt werden, während zu diesem Zeitpunkt das Virus in Blutproben nicht nachweisbar war. Somit scheint eine Bestimmung des viralen Genoms im Urin v. a. bei einer länger zurückliegenden Infektion sinnvoll zu sein.

\section{》) Die virale RNA kann bis zu 3 Wochen nach Beginn der klinischen Symptome im Urin nachgewiesen werden}

Der erste Anhaltspunkt auf eine Infektion ist aufgrund der uncharakteristischen Symptome anamnestisch eine kürzlich durchgeführte Reise in Endemiegebiete (• Abb. 1). Dabei sollte ebenfalls auf- grund einer möglichen sexuellen Übertragung auch ein eventueller Aufenthalt des Sexualpartners in "Zika-Virus-Gebieten" bedacht werden.

Zu Beginn der Erkrankung lässt sich das Virus im Blut und im Urin direkt nachweisen (reverse Transkription mit nachfolgender Polymerase-Kettenreaktion, RT-PCR). Demzufolge wird bis zum 7. Tag nach Beginn der Symptome ein Virusnachweis aus Serum bzw. Plasma sowie Urin empfohlen. Vom 8. bis zum 27. Tag sollten ein Genomnachweis nur aus dem Urin sowie eine Antikörperbestimmung (IgM und IgG) aus dem Serum erfolgen. Falls der Symptombeginn länger als 28 Tage zurückliegt, kommt nur eine serologische Bestimmung (IgMund IgG-Antikörper) zum Nachweis einer akuten bzw. abgelaufenen Infektion in Betracht (• Abb. 1).

Prinzipiell kann bei Reiserückkehrern mit symptomatischer Erkrankung eine Diagnostik durchgeführt werden. Falls Reiserückkehrer keine Symptome zeigen, erscheint eine serologische Untersuchung nur bei aktuell schwangeren Frauen bzw. deren Geschlechtspartnern sinnvoll ([19, 20, 47, 59]; • Abb. 1).

\section{Schwangere mit Reiseanamnese in Endemiegebiete}

Schwangere, die kürzlich eine Reise in Endemiegebiete hinter sich haben, können getestet werden $[47,55]$. Dabei ist $\mathrm{zu}$ beachten, ob die Schwangeren klinische Symptome aufweisen oder nicht (- Infobox 1). Während das Center of Disease Control (CDC) den relevanten Zeitraum der zurückliegenden Reise auf 2-12 Wochen definiert [47, 55], gibt das Bernhard-Nocht-Institut für Tropenmedizin die zurückliegende Reise innerhalb der letzten 3 Wochen als sinnvollen Zeitraum für eine Testung an [8].

\section{Ultraschalluntersuchungen}

Erweiterte Ultraschalluntersuchungen werden für alle Schwangeren empfohlen, die in Zika-Virus-Endemiegebieten leben oder dorthin gereist sind. Schwangere mit Exposition zu Zika-Virus sollten eine Basisultraschalluntersuchung erhalten [6]. Es erscheint sinnvoll, die 1. Ultraschalluntersuchung 3-4 Wo- chen nach Auftreten der Symptome bzw. nach der Reise durchzuführen [35]. Bei Schwangerschaften $>14+0$ Schwangerschaftswochen (SSW) sollte diese:

- eine allgemeine Beurteilung der fetalen Anatomie;

- eine fetale Biometrie mit Bestimmung des biparietalen Durchmessers (BPD), des Kopfumfangs (KU), des Abdomenumfangs (AU), der Femurlänge (FL) und des transzerebellären Durchmessers (TCD) sowie

- eine gezielte Beurteilung der zerebralen Anatomie (Weite der Seitenventrikel, Suche nach Echogenitätsvermehrung)

beinhalten $[19,54]$. Da die häufigsten Auffälligkeiten das fetale Gehirn betreffen, sollte sich der Fokus der Ultraschalluntersuchung $u$. a. auch auf intrakranielle Verkalkungen, Mikrozephalie bzw. auch andere sonographische Auffälligkeiten erstrecken.

Bei Müttern mit positivem Testergebnis sollten sequenzielle Ultraschalluntersuchungen alle 3-4 Wochen erfolgen. Auch Schwangere, die negativ getestet wurden, aber eine positive Reiseanamnese haben, könnten ebenfalls mit sequenziellen Ultraschalluntersuchungen beobachtet werden, da der Verlauf einer Zika-Virus-Infektion und die klinische Manifestation beim ungeborenen Kind derzeit noch unklar sind. Allerdings gibt es für die sonographischen Kontrolluntersuchungen dieser Schwangeren derzeit keine Empfehlungen. Ein negativer Zika-Virus-IgM-Befund 2-12 Wochen nach einer Reise kann eine Zika-VirusInfektion nicht komplett ausschließen, wobei allerdings serielle Ultraschalluntersuchungen überflüssig werden.

Mittlerweile wurden auch Empfehlungen für die sonographische Beurteilung und Diagnose einer Mikrozephalie während der Schwangerschaft veröffentlicht $[1,54,61]$. Falls auffällige Befunde auftreten, könnte eine Amniozentese mit einer Zika-Virus-Testung erfolgen. Allerdings sind einige Aspekte, wie z. B. die Dauer einer möglichen vertikalen Transmission nach mütterlicher Primärinfektion oder die Sensitivität und Spezifität einer RT-PCR in der Amnionflüssigkeit, noch weitgehend unklar. Ebenfalls wä- 


\section{Infobox 2 Wirksame Maß- nahmen zur Vermeidung von Mückenstichen}

- Meidung von ruhenden/stillen Gewässern. - Nutzung von Moskitonetzen; häufig wird eine Imprägnierung mit Insektiziden (z. B. Permethrin) empfohlen.

- Bedeckung des Körpers mit Kleidung (z. B. lange Hosen und Hemden).

- Dabei ist zu beachten, dass die Mücken, die das Zika-Virus übertragen, auch weitere Viren (Dengue-Virus und Chikungunya-Virus) übertragen können und tagaktiv sind. Somit sollte die lange Kleidung v. a. tagsüber und in den Abendstunden getragen werden.

- Schutz von Hautstellen, die nicht durch Kleidung bedeckt sind, durch Gebrauch eines Antimückensprays (Repellent).

- Aufenthalt in geschlossenen Räumen mit Insektengitter oder Klimaanlage.

re eine fetales Magnetresonanztomographie (MRT) möglich, um das genaue Ausmaß bzw. weitere Auffälligkeiten zu evaluieren [54].

\section{Neugeborene}

Mittlerweile sind v. a. aus dem amerikanischen Bereich Empfehlungen über das Vorgehen bei Neugeborenen aus Risikoschwangerschaften erschienen [62]. Demnach sollten Neugeborene von Frauen mit einer Reise in Endemiegebieten, die während der Schwangerschaft eine fetale Mikrozephalie bzw. andere sonographische ZNS-Auffälligkeiten zeigen, bzw. Neugeborene von positiv bzw. unklar getesteten Schwangeren untersucht werden. Eine Testung des Neugeborenen mittels RT-PCR und IgM-Antikörper auf Zika-Virus sollte möglichst innerhalb der ersten 2 Tage nach Geburt erfolgen. Ebenfalls sollte eine Testung auf IgM-Antikörper gegen das Dengue-Virus durchgeführt werden. Die amerikanische Leitlinie empfiehlt ebenfalls die histopathologische Evaluation der Plazenta bzw. der Nabelschnur mit immunhistochemischen bzw. molekularbiologischen Methoden an paraffinfixiertem bzw. gefrorenem Gewebe. Solche Untersuchungen sind aber häufig nur in Speziallaboren möglich.

\section{Therapie}

Es gibt keine gezielte Therapie einer Zika-Virus-Infektion. Eine manifeste Erkrankung wird symptomatisch mit Schmerzmitteln, fiebersenkenden Medikamenten und der Zufuhr von reichlich Flüssigkeit behandelt. Allerdings sollte der Einsatz von nichtsteroidalen Antirheumatika (NSAR) aufgrund ihrer gerinnungshemmenden Wirkung erst nach Ausschluss eines Dengue-Fiebers erfolgen. Da Paracetamol keine Gerinnungskomponente besitzt, wäre diesem NSAR, v. a. während einer Schwangerschaft, der Vorzug zu geben.

Eine aktive oder passive Immunisierung steht derzeit nicht zur Verfügung. Eine bereits durchgemachte Zika-VirusInfektion schützt aller Voraussicht nach vor einer weiteren Infektion mit demselben Erreger.

\section{Prävention}

\section{Schwangerschaft nach abgelaufener Zika-Virus-Infektion}

Eine bereits durchgemachte Zika-VirusInfektion scheint kein erhöhtes Risiko für eine zukünftige Schwangerschaft darzustellen [47]. Es gibt keinerlei Hinweise, dass eine abgelaufene Infektion vor der Schwangerschaft zu einem erhöhten Risiko von kindlichen Fehlbildungen führt. Allerdings wird empfohlen, bis etwa 8 Wochen nach letzter Exposition keine Schwangerschaft anzustreben [47].

\section{Frauen mit Kinderwunsch}

Frauen mit Kinderwunsch sollten mindestens 8 Wochen nach Symptombeginn warten, um schwanger zu werden. Bei Männern liegt der derzeitige empfohlene Zeitraum bei 6 Monaten. Diese Zeiträume basieren auf einer Berechnung der höchstmöglichen Inkubationszeit von 2 Wochen sowie der Verdreifachung der längsten vorläufig beobachteten Virämie von 11 Tagen. Dabei wird bei Paaren mit bestehendem Kinderwunsch nach einer Reise in Endemiegebiete ohne klinische Symptome keine Zika-Virus-Testung empfohlen [28, 47, 55].
Schutz des Personals in geburtshilflichen Einheiten

Auf den geburtshilflichen Stationen und in Kreißsälen sollten die regulären Vorsichtsmaßnahmen und Hygienevorschriften beachtet werden [50].

\section{Übertragung durch Geschlechts- verkehr}

Da eine Übertragung durch Geschlechtsverkehr möglich ist, sind mittlerweile einige Empfehlungen zur Prävention erschienen [52]. Männer von schwangeren Frauen, die in Zika-Virus-Endemiegebieten wohnen oder dorthin reisen, sollten entweder keinen Geschlechtsverkehr haben oder konsequent Kondome über den gesamten Zeitraum der Schwangerschaft nutzen [52].

\section{Vermeidung von Reisen}

Fast alle nationalen und internationalen Organisationen empfehlen, berufliche und private Reisen in Zika-Virus-Endemiegebiete während der Schwangerschaft zu vermeiden. Auch das Auswärtige Amt der Bundesrepublik Deutschland [5], die Deutsche Gesellschaft für Tropenmedizin [20] sowie die Deutsche Gesellschaft für Gynäkologie und Geburtshilfe (DGGG) raten Schwangeren von Reisen in Verbreitungsgebiete des Zika-Virus ab.

\section{Vermeidung von Mückenstichen}

Ist eine Reise in Endemiegebiete nicht vermeidbar, sollten Vorkehrungen zum Schutz vor Mückenstichen getroffen werden. Auch Personen, die gerade eine Zika-Virus-Infektion durchmachen oder gerade aus Endemiegebieten zurückkehren, sollten sich vor Mückenstichen schützen, um eine Weiterverbreitung des Virus zu vermeiden ( Infobox 2).

\section{Globale Großveranstaltungen}

Da das Zika-Virus sich rasant weltweit ausbreitet, wurden zahlreiche Beurteilungen zur möglichen Ausbreitung über Großveranstaltungen, wie die Olympischen und Paraolympischen Spiele in Brasilien diskutiert. Nach Zusammentra- 


\section{Infobox 3 Weiterführende internetbasierte Literatur}

Allgemeine Informationen

- Bernhard-Nocht-Institut für Tropenmedizin: www.bnitm.de. Zugegriffen: 26. August 2016

- Centers for Disease Control and Prevention (CDC): http://www.cdc.gov. Zugegriffen: 26. August 2016

- Deutsche Gesellschaft für Tropenmedizin (DTG): www.dtg.org. Zugegriffen: 26. August 2016

- Europäisches Zentrum für die Prävention und Kontrolle von Krankheiten (ECDC): http://ecdc.europa.eu/en/Pages/home. aspx. Zugegriffen: 26. August 2016

- Pan American Health Organization: www. paho.org. Zugegriffen: 26. August 2016

- Robert Koch-Institut (RKI): www.rki.de. Zugegriffen: 26. August 2016

- Weltgesundheitsorganisation (WHO): www.who.int. Zugegriffen: 26. August 2016

- Deutsche Gesellschaft für Gynäkologie und Geburtshilfe (DGGG): www.dggg.de. Zugegriffen: 26. August 2016

Aktuelle Karten zu Ländern mit bekannter Übertragung

- Weltgesundheitsorganisation (WHO): http://www.paho.org/hq/ index.php?option=com_content\& view $=$ article\&id $=11603 \&$ Itemid $=41696$. Zugegriffen: 26. August 2016

- Europäisches Zentrum für die Prävention und Kontrolle von Krankheiten (ECDC): http://ecdc.europa.eu/en/ healthtopics/zika_virus_infection/zikaoutbreak/Pages/zika-outbreak.aspx. Zugegriffen: 26. August 2016

gen aller Informationen zur internationalen Ausbreitung, Großveranstaltungen, reisemedizinische Besonderheiten u. a. ist das Internationale Olympische Komitee zu dem Schluss gekommen, dass das Risiko einer Ausbreitung des Zika-Virus als Folge der internationalen Veranstaltung der Olympischen und Paraolympischen Spiele in Brasilien nur gering ist. Einerseits wird die Übertragung der Viren im brasilianischen Winter als (im Vergleich zum Sommer) geringer eingestuft und andererseits werden die verstärkten Kontrollmaßnahmen zur Verminderung der Ausbreitung der Vektoren in und um die Austragungsorte weiterhin durchgeführt, sodass das Übertragungsrisiko weiter reduziert wird [67].
Mittlerweile sind etliche Maßnahmen in den allgemeinen Medien bekannt geworden. So möchte das brasilianische Organisationskomitee unter den Sportlerinnen und Sportlern kostenlos Kondome verteilen. Ebenso sollte im Olympischen Dorf nun jedes Zimmer, im Vergleich zur vorangegangenen Planung, mit einer Kühlanlage (Aircondition) ausgestattet werden. Aus diesem Grund gab es keinen Anhalt, die Olympischen Spiele zeitlich oder geographisch zu verschieben. Mittlerweile sind die Olympischen Spiele in Rio/Brasilien erfolgt, ohne dass von vermehrten Zika-Virus-Infektionen und möglichen Komplikationen berichtet wurde. Allerdings gelten weiterhin die Vorsichtsmaßnahmen wie z. B. die Vermeidung von Reisen in Endemiegebieten von Schwangeren.

Weiterführende Literatur ist - Infobox 3 zu entnehmen.

\section{Fazit für die Praxis}

- Die Übertragung des Zika-Virus erfolgt über infizierte Mücken (insbesondere Aedes aegypti). Auch eine Übertragung durch Geschlechtsverkehr ist möglich. Zika-VirusEndemiegebiete liegen derzeit v. a. auf dem amerikanischen Kontinent. Das Erkrankungsrisiko in Europa ist gering.

- Die Zika-Virus-Infektion verläuft meist a- bis oligosymptomatisch, ist aber auch mit einer Reihe von neurologischen Erkrankungen (z. B. Guillain-Barré-Syndrom) beim Erwachsenen assoziiert. Schwangere haben insbesondere im 1. Trimenon ein erhöhtes Risiko für die Entwicklung einer fetalen Mikrozephalie.

- Das Virus kann molekularbiologisch oder durch Antikörpertestung nachgewiesen werden. Bei Schwangeren mit positivem Testergebnis werden regelmäßige Ultraschalluntersuchungen empfohlen.

- Schwangere sollten Reisen in Endemiegebiete meiden. Aus Endemiegebieten kommende oder dort wohnende Partner von Schwangeren sollten über den gesamten Zeitraum der Schwangerschaft bei
Geschlechtsverkehr konsequent Kondome nutzen.

\section{Korrespondenzadresse}

Prof. Dr. med. Dr. h.c. I. Mylonas

Klinik und Poliklinik für Frauenheilkunde und Geburtshilfe - Klinikum Innenstadt, LudwigMaximilians-Universität München Maistraße 11, 80337 München, Deutschland ioannis.mylonas@med.uni-muenchen.de

Interessenkonflikt. I. Mylonas, S. Dieterle, M. Hampl, U.B. Hoyme, J. Jückstock, W. Mendling, G. Neumann und K. Friese geben an, dass kein Interessenkonflikt besteht.

\section{Literatur}

1. ACOG, SMFM (2016) Practice advisory: Updated interim guidance for care of obstetric patients and women of reproductive age during a Zika virus outbreak. http://www. acog.org/About-ACOG/News-Room/PracticeAdvisories/Practice-Advisory-Interim-Guidancefor-Care-of-Obstetric-Patients-During-a-ZikaVirus-Outbreak

2. Alera MT, Hermann L, Tac-An IA et al (2015) Zika virus infection, Philippines, 2012. Emerging Infect Dis 21:722-724

3. Ashwal S, Michelson D, Plawner L et al (2009) Practice parameter: Evaluation of the child with microcephaly (an evidence-based review): Report of the Quality Standards Subcommittee of the American Academy of Neurology and the Practice Committee of the Child Neurology Society. Neurology 73:887-897

4. Atkinson B, Hearn P, Afrough B et al (2016) Detection of Zika Virus in Semen. Emerging Infect Dis 22(5):940-940 (Auswärtiges Amt (Aa) (2016) Gesundheitsdienst - 04/16/JS/GB - Merkblatt für Beschäftigte) doi:10.3201/eid2205.160107

5. Auswärtiges Amt (2016) Reisendeeisende - Zika-Virus-Infektion. April 2016. www. auswaertigesamt.de/cae/servlet/contentblob/ 722280/publicationFile/212139/Zika-Virus.pd

6. Baud D, Van Mieghem T, Musso D et al (2016) Clinical management of pregnantwomen exposed to Zika virus. Lancet Infect Dis 16(5):523. doi:10. 1016/s1473-3099(16)30008-1

7. Bearcroft WG (1956) Zika virus infection experimentally induced in a human volunteer. Trans $\mathrm{R}$ Soc Trop Med Hyg 50:442-448

8. Bernhard-Nocht-Institut Für Tropenmedizin (BNITM) (2016) Empfehlungen zur Diagnostik der Zika Virus Infektion. 9. Februar 2016. https:// www.bnitm.de/aktuelles/mitteilungen/954empfehlungen-zurdiagnostik-der-zika-virusinfektion/

9. Besnard M, Lastere S, Teissier A et al (2014) Evidence of perinatal transmission of Zika virus, French Polynesia, December 2013 and February 2014. Euro Surveill 19(13):20751. doi:10.2807/ 1560-7917.es2014.19.13.20751

10. Brasil P, Pereira JP Jr., Raja Gabaglia C et al (2016) Zika virus infection in pregnant women in Rio de Janeiro - preliminary report. N Engl J Med. doi:10. 1056/nejmoa1602412

11. Cao-Lormeau VM, Blake A, Mons S et al (2016) Guillain-Barre Syndrome outbreak associated with 
Zika virus infection in French Polynesia: A casecontrol study. Lancet 387:1531-1539

12. Cao-Lormeau VM, Roche C, Teissier A et al (2014) Zika virus, French polynesia, South Pacific, 2013. Emerging Infect Dis 20:1085-1086

13. Cauchemez S, Besnard M, Bompard P et al (2016) Association between Zika virus and microcephaly in French Polynesia, 2013-15: A retrospective study. Lancet 387:2125-2132

14. Cordeiro MT, Pena LJ, Brito CA et al (2016) Positive IgM for Zika virus in the cerebrospinal fluid of 30 neonates with microcephaly in Brazil. Lancet 387:1811-1812

15. Cugola FR, Fernandes IR, Russo FB et al (2016) The Brazilian Zika virus strain causes birth defects in experimental models. Nature 534:267-271

16. D'ortenzio E, Matheron S, Yazdanpanah $Y$ et al (2016) Evidence of sexual transmission of Zika virus. N Engl J Med 374:2195-2198

17. De MCR, Cirne-Santos C, Meira GL et al (2016) Prolonged detection of Zika virus RNA in urine samples during the ongoing Zika virus epidemic in Brazil. JClin Virol 77:69-70

18. Derraik JG, Slaney D (2015) Notes on Zika virus an emerging pathogen now present in the South Pacific. Aust NZJ Public Health 39:5-7

19. Deutsche Gesellschaft Für Gynäkologie Und Geburtshilfe E. V. (Dggg) (2016) Schwangere sollten sich nach Fernreisen in Epidemiegebiete auf Zikavirus-Infektion testen lassen. In: Empfehlungen der Deutschen Gesellschaft für Gynäkologie und Geburtshilfee. V.

20. Deutsche Gesellschaft Für Tropenmedizin (Dgtm) (2016) Aktualisierung zu Zika. 14. März 2016. http://www.dtg. org/24.html?\&tx_ttnews[tt_news]=136\& cHash $=$ cd8002635595379205e7612258861c95

21. Dick GW (1952) Zika virus. II. Pathogenicity and physical properties. Trans R Soc Trop Med Hyg 46:521-534

22. Dick GW (1953) Epidemiological notes on some viruses isolated in Uganda; Yellow fever, Rift Valley fever, Bwamba fever, West Nile, Mengo, Semliki forest, Bunyamwera, Ntaya, Uganda S and Zika viruses. Trans R Soc Trop Med Hyg 47:13-48

23. Dick GW, Kitchen SF, Haddow AJ (1952) Zika virus. I. Isolations and serological specificity. Trans R Soc Trop Med Hyg 46:509-520

24. Duffy MR, Chen TH, Hancock WT et al (2009) Zika virus outbreak on Yap Island, Federated States of Micronesia. NEngl J Med 360:2536-2543

25. Fleming-Dutra KE, Nelson JM, Fischer $M$ et al (2016) Update: Interim Guidelines for Health Care Providers Caring for Infants and Children with Possible Zika Virus Infection - United States, February 2016. MMWR Morb Mortal Wkly Rep 65:182-187

26. Foy BD, Kobylinski KC, Chilson Foy JL et al (2011) Probable non-vector-borne transmission of Zika virus, Colorado, USA. Emerging Infect Dis 17:880-882

27. Frank C, Cadar D, Schlaphof A et al (2016) Sexual transmission of Zika virus in Germany, April 2016. Euro Surveill. doi:10.2807/1560-7917.es.2016.21. 23.30252

28. Friese K, Mylonas I, Schulze A (2013) Infektionserkrankungen der Schwangeren und des Neugeborenen. Springer-Verlag, Berlin Heidelberg

29. Gourinat AC, O'connor O, Calvez E et al (2015) Detection of Zika virus in urine. Emerging Infect Dis 21:84-86

30. Gulland A (2016) WHO warns of risk of Zika virus in Europe. BMJ 353:i2887. doi:10.1136/bmj.i2887
31. Heang V, Yasuda CY, Sovann Let al (2012) Zika virus infection, Cambodia, 2010. Emerging Infect Dis 18:349-351

32. Hills SL, Russell K, Hennessey M et al (2016) Transmission of Zika virus through sexual contact with travelers to areas of ongoing transmission - continental united states, 2016. MMWR Morb Mortal Wkly Rep 65:215-216

33. loos S, MalletHP, LeparcGoffartletal (2014)Current Zika virus epidemiology and recent epidemics. Med Mal Infect 44:302-307

34. Johansson MA, Mier-y-Teran-Romero L, Reefhuis $J$ et al (2016) Zika and the risk of microcephaly. NEngl J Med. doi:10.1101/051060

35. Lanciotti RS, Kosoy OL, Laven JJ et al (2008) Genetic and serologic properties of Zika virus associated with an epidemic, Yap State, Micronesia, 2007. Emerging Infect Dis 14:1232-1239

36. Mansuy JM, Dutertre $M$, Mengelle $C$ et al (2016) Zika virus: High infectious viral load in semen, a new sexually transmitted pathogen? Lancet Infect Dis 16:405

37. Marano G, Pupella S, Vaglio S et al (2016) Zika virus and the never-ending story of emerging pathogens and transfusion medicine. Blood Transfus 14:95-100

38. Mccarthy M (2016) Zika virus was transmitted by sexual contact in Texas, health officials report. BMJ 352:i720. doi:10.1136/bmj.i720

39. Miner JJ, Cao B, Govero J et al (2016) Zika virus infection during pregnancy in mice causes placenta damage and fetal demise. Cell 165:1081-1091

40. Musso D (2015) Zika virus transmission from french polynesia to Brazil. Emerging Infect Dis 21(10):1887-1887. doi:10.3201/eid2010.151125

41. Musso D, Gubler DJ (2016) Zika virus. Clin Microbiol Rev 29:487-524

42. Musso D, RocheC, Nhan TXetal (2015) Detection of Zika virus in saliva. J Clin Virol 68:53-55

43. Musso D, Roche C, Robin E et al (2015) Potential sexual transmission of Zika virus. Emerging Infect Dis 21:359-361

44. Neu N, Duchon J, Zachariah P (2015) TORCH infections. Clin Perinatol 42:77-103 (viii)

45. Nishiura H, Mizumoto K, Rock KS et al (2016) A theoretical estimate of the risk of microcephaly during pregnancy with Zika virus infection. Epidemics 15:66-70

46. Noronha L, Zanluca C, Azevedo ML et al (2016) Zika virus damages the human placental barrier and presents marked fetal neurotropism. Mem Ins Oswaldo Cruz 111:287-293

47. Oduyebo T, Petersen EE, Rasmussen SA et al (2016) Update: interim guidelines for health care providers caring for pregnant women and women of reproductive age with possible Zika virus exposure - United States, 2016. MMWR Morb Mortal Wkly Rep 65:122-127

48. Oehler E, Watrin L, Larre P et al (2014) Zika virus infection complicated by Guillain-Barre syndrome - case report, French Polynesia, December 2013. Euro Surveill 19(9):20720. doi:10.2807/1560-7917. es2014.19.9.20720

49. Oliveira Melo AS, MalingerG, Ximenes Retal (2016) Zika virus intrauterine infection causes fetal brain abnormality and microcephaly: Tip of the iceberg? Ultrasound Obstet Gynecol 47:6-7

50. Olson CK, Iwamoto M, Perkins KM et al (2016) Preventing transmission of Zika virus in labor and delivery settings through implementation of standard precautions - United States, 2016. MMWR Morb Mortal Wkly Rep 65:290-292

51. Olson JG, Ksiazek TG, Suhandiman et al (1981) Zika virus, a cause of fever in central Java, Indonesia. Trans RSoc Trop Med Hyg 75:389-393
52. Oster AM, Brooks JT, Stryker JE et al (2016) Interim guidelines for prevention of sexual transmission of Zika virus - United States, 2016. MMWR Morb Mortal Wkly Rep 65:120-121

53. Pacheco O, Beltran M, Nelson CA et al (2016) Zika virus disease in Colombia - preliminary report. NEngl J Med. doi:10.1056/nejmoa1604037

54. Papageorghiou AT, Thilaganathan B, Bilardo CM et al (2016) ISUOG Interim Guidance on ultrasound for Zika virus infection in pregnancy: Information for healthcare professionals. Ultrasound Obstet Gynecol 47:530-532

55. Petersen EE, Staples JE, Meaney-Delman D et al (2016) Interim guidelines for pregnant women during a Zika virus outbreak - United States, 2016 MMWR Morb Mortal Wkly Rep 65:30-33

56. Quicke KM, Bowen JR, Johnson EL et al (2016) Zika virus infects human placental macrophages. Cell Host Microbe 20(1):83-90. doi:10.1016/j.chom. 2016.05.015

57. Rasmussen SA, Jamieson DJ, Honein MA et al (2016) Zika virus and birth defects - reviewing the evidencefor causality. NEnglJMed 374:1981-1987

58. Reusken C, Pas S, Geurtsvankessel C et al (2016) Longitudinal follow-up of Zika virus RNA in semen of a traveller returning from Barbados to the Netherlands with Zika virus disease, march 2016. Euro Surveill. doi:10.2807/1560-7917.es.2016.21. 23.30251

59. Schuler-Faccini L, Ribeiro EM, Feitosa IMetal (2016) Possible association between Zika virus infection and microcephaly - Brazil, 2015. MMWR Morb Mortal Wkly Rep 65:59-62

60. Simpson DI (1964) Zika virus infection in man. Trans R Soc Trop Med Hyg 58:335-338

61. Society for Maternal-Fetal Medicine (SMFM) Publications Committee (2016) Ultrasound screening for fetal microcephaly following Zika virus exposure. Am JObstet Gynecol 214:B2-B4. doi:10.1016/ j.ajog.2016.02.043

62. Staples JE, Dziuban EJ, Fischer Metal (2016) Interim guidelines for the evaluation and testing of infants with possible congenital Zika virus infection United States, 2016. MMWR Morb Mortal Wkly Rep 65:63-67

63. Venturi G, Zammarchi L, Fortuna C et al (2016) An autochthonous case of Zika due to possible sexual transmission, Florence, Italy, 2014. Euro Surveill. doi:10.2807/1560-7917.es.2016.21.8.30148

64. Wiwanitkit V (2016) Placenta, Zika virus infection and fetal brain abnormality. Am J Reprod Immunol 76(2):97-98. doi:10.1111/aji.12521

65. World Health Organization (Who) (2016) WHO statement on the first meeting of the International Health Regulations (2005) (IHR 2005) Emergency Committee on Zika virus and observed increase in neurological disorders and neonatal malformations. 1st February 2016. http://www. who.int/mediacentre/news/statements/2016/ 1st-emergency-committee-zika/en/

66. World Health Organization (WHO) (2016) Zika situation report: Zika virus, Microcephaly and Guillain-Barré syndrome. 21st April 2016. http:// apps.who.int/iris/bitstream/10665/205505/1/ zikasitrep_21Apr2016_eng.pdf?ua=1

67. World Health Organization (WHO) (2016) Zika situation report: Zika virus, microcephaly and Guillain-Barré syndrome. 16th June 2016. http:// apps.who.int/iris/bitstream/10665/242439/1/ zikasitrep-16Jun2016-eng.pdf?ua $=1$

68. Zanluca C, Melo VC, Mosimann AL et al (2015) First report of autochthonous transmission of Zika virus in Brazil. Mem Inst Oswaldo Cruz 110:569-572 